REYTORDS:

Physics

Reactor Safety

Mark 22

\section{RETENTION :}

CLASSIFICATION :

UNCLASSIFIED

\title{
K-14 SHUTDOWN REACTIVITY (U)
}

\author{
BY
}

JOHN R. CHANDLER

ISSUED: October 31, 1990

\section{DISCLAIMER}

\begin{abstract}
This report was prepared as an account of work sponsored by an agency of the United States Government. Neither the United States Government nor any agency thereof, nor any of their employees, makes any warranty, express or implied, or assumes any legal liability or responsibility for the accuracy, completeness, or usefulness of any information, apparatus, product, or process disclosed, or represents that its use would not infringe privately owned rights. Reference herein to any specific commercial product, process, or service by trade name, trade nark, manufacturer, or otherwise does not necessarily constitute or imply its endorsement, ricommendation, or favoring by the United States Government or any agency thereof. The views and opinions of authors expressed herein do not necessarily state or reflect those of the United States Government or any agency thereof.
\end{abstract}

\section{APPROVALS}

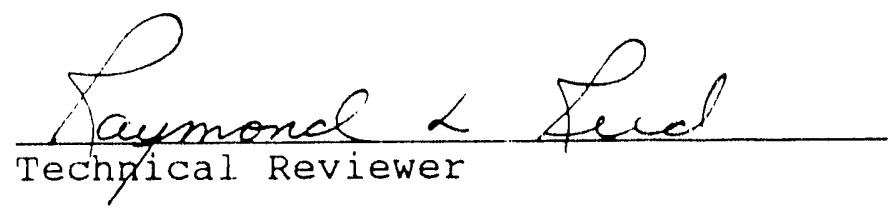

Date: $10,31 / 90$

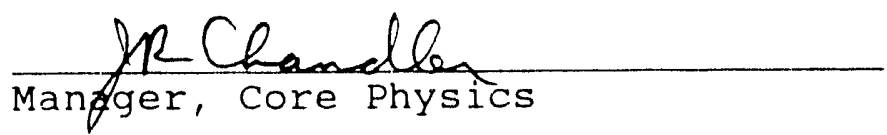

Date: $\quad 10 / 31 / 90$

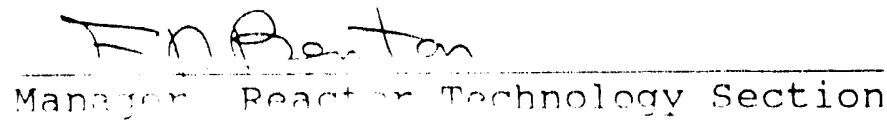

Date: $|0-3|-9 m$ 
WSRC-TR-90-42-137

October 31,1990

TO: F. BERANEK, 704-C

FROM: J.R. CHANDLER, 707-C

R-14 SHUTDOWN REACTIVITY

INTRODUCTION AND SUMMARY

SRS reactor charges are designed to ensure the reactor remains subcritical during chargeback and shutdown conditions. calculations have recently been performed to determine the shutdown $k_{\text {eff }}$ for the $\mathrm{K}-14$ charge. This aocument discusses the results and uncertainties.

\section{SUMMARY}

The best estimate for $\mathrm{K}-14$ shutdown $\mathrm{k}_{\text {eff }}$ is 0.9411 . Uncertainty in keff from reactivity calculations, control rod contents, safety rod worth, and assembly contents is 0.0169 at the 95\% confidence level and 0.0279 at the $99 \%$ confidence level. Maximum shutdown keff is therefore 0.9580 with $95 \%$ confidence and 0.9690 with $99 \%$ confidence.

\section{DISCUSSION}

\section{Best Estimate Shutdown Reactivity}

The shutdown K-14 keff has been evaluated using the GLASS and GRIMHX computer codes with the method described in Reference 2 . The calculated $k_{\text {eff }}$ is 0.9275 .2 The calculation used the fabricated contents as reported in Reference 3 . Input to these calculations includes a cross section modification factor to account for the presence of safety rods. The factor used in the calculations corresponds to the best estimate safety rod worth. 4

Calculational bias of GRIMHX is nearly the same as for MARCO. 5 This bias has been determined to be $0.0136 .^{6}$ Adding the bias to the calculated value yields 0.9411 , the best estimate for $\mathrm{K}-14$ shutdown keff.

\section{Calculation uncertainties}

Reactivity predictions contain uncertainties due to methodology, nuclear data, and contents for fuel tubes, target tubes, and control rods. It is not possible to comp tely separate these uncertainties. I'hus they were all lumped into calculation uncertainties and evaluated as one. 
WSRC-TR-90-42-137

October 31, 1990

Page 2 of 4

The observed critical position from nine past Mark 22 cores has been used to determine the uncertainties in calculation bias for several different confidence intervals. 6 This evaluation determined the uncertainty of the calculational bias discussed above. The uncertainty is given in Reference 6 in terms of tolerance intervals. Tolerance intervals describe the expected variation in individual future observations. They are limits which bound a proportion of individuals with a given probability. The choice of population proportion and probability is arbitrary. For simplicity I will adopt the definition that $95 \%$ confidence is a $95 \%$ proportion of future observations with a $95 \%$ probability. Using this definition the $95 \%$ confidence level uncertainty in $k_{\text {eff }}$ is 0.0157 delta-k/keff. 6 The $99 \%$ conf $\frac{j}{6}$ dence level uncertainty in $k_{\text {eff }}$ is 0.0265 delta-k/keff.

\section{Safety Rod Worth}

The data in Reference 6 is for observed critical and therefore does not include safety rods. Safety rod uncertainties must be considered separately. The calculated best estimate shutdown keff using the GRIMHX code is 0.9275 .2 The shutdown calculation using best estimate safety rod worth minus 2 sigma yields $0.9357 .2,4$ The uncertainty in the safety rod worth is the difference $(0.0082$ delta-k) between these two values. Thus the uncertainty at the $95 \%$ confidence level can be expressed as 0.0088 delta-k/keff for all values of $k$ eff. The corresponding uncertainty at the $99 \%$ confidence level ( 3 sigma uncertainty) can be determined from the $95 \%$ confidence level ( 2 sigma uncertainty) as 0.0132 delta-k/keff.

\section{Significance}

The uncertainties described above are summarized in Table 1. The net effect of uncertainties was determined by taking the square root of the sum of the squares. The net uncertainty in shutdown 1 . fif is secn to be 0.0169 at the $95 \%$ confidence level and 0.0279 at the $99 \%$ confidence level. The estimate for maximum shutdown keff is therefore 0.9580 (95\% confidence level) or 0.9690 (99\% confidence level). 
WSRC-TR-90-42-137

October 31, 1990

Page 3 of 4

\section{REFERENCES}

1. R. A. Bond, $\mathrm{K}-14$ Chargeback Predictions, WSRC-TR-90-42-046, June 29,1990 .

2. R. A. Bond, $\mathrm{K}-14$ Shutdown Calculation Notes, OpS-RTS-900168, October 17, 1990 .

3. K-14 Mark 22 Charge Match List, Rev.2, ID\#06/20/90 15:36:01:86, June 20, 1990 (Confidential).

4. P. B. Parks, W. E. Graves, and N. H. Kuehn, Estimates of the Safety Rod Timing, Worth and Post-Power Peaking In Mark 22 Charges, DPSP-88-865, January, 1989, and Addendum 1, March, 1989.

5. R. L. Webb, The Mark 22 MARCO Library and Recent Updating of the MARCO Code, DPST-86-234, January 15, 1986.

6. R. L. Webb, Uncertainties and Bias In Mark 22 MARCO Calculations, DPST-88-859, November, 1988 . 
WSRC-TR-90-42-137

October 31, 1990

Page 4 of 4
TABLE 1

$\underline{\text { K-14 Shutdown Reactivity }}$
Value

0.9275

$+0.0136$

0.9411

$\pm 0.0169$

$\pm 0.0279$

\section{Comments}

Calculated keff with all control \& safety rods inserted. Includes best estimate safety rod worth.

Correction for calculational bias.

Best estimate shutdown keff.

Uncertainty for $95 \%$ confidence $(0.0180$ delta-k/keff). This includes 0.0157 delta-k/keff calculational uncertainty and 0.0088 delta-k/keff uncertainty for safety rod worth.

Uncertainty for $99 \%$ confidence $(0.0296$ delta-k/keff). This includes 0.0265 delta-k/keff calculational uncertainty and 0.0132 delta-k/keff uncertainty for safety rod worth. 
A
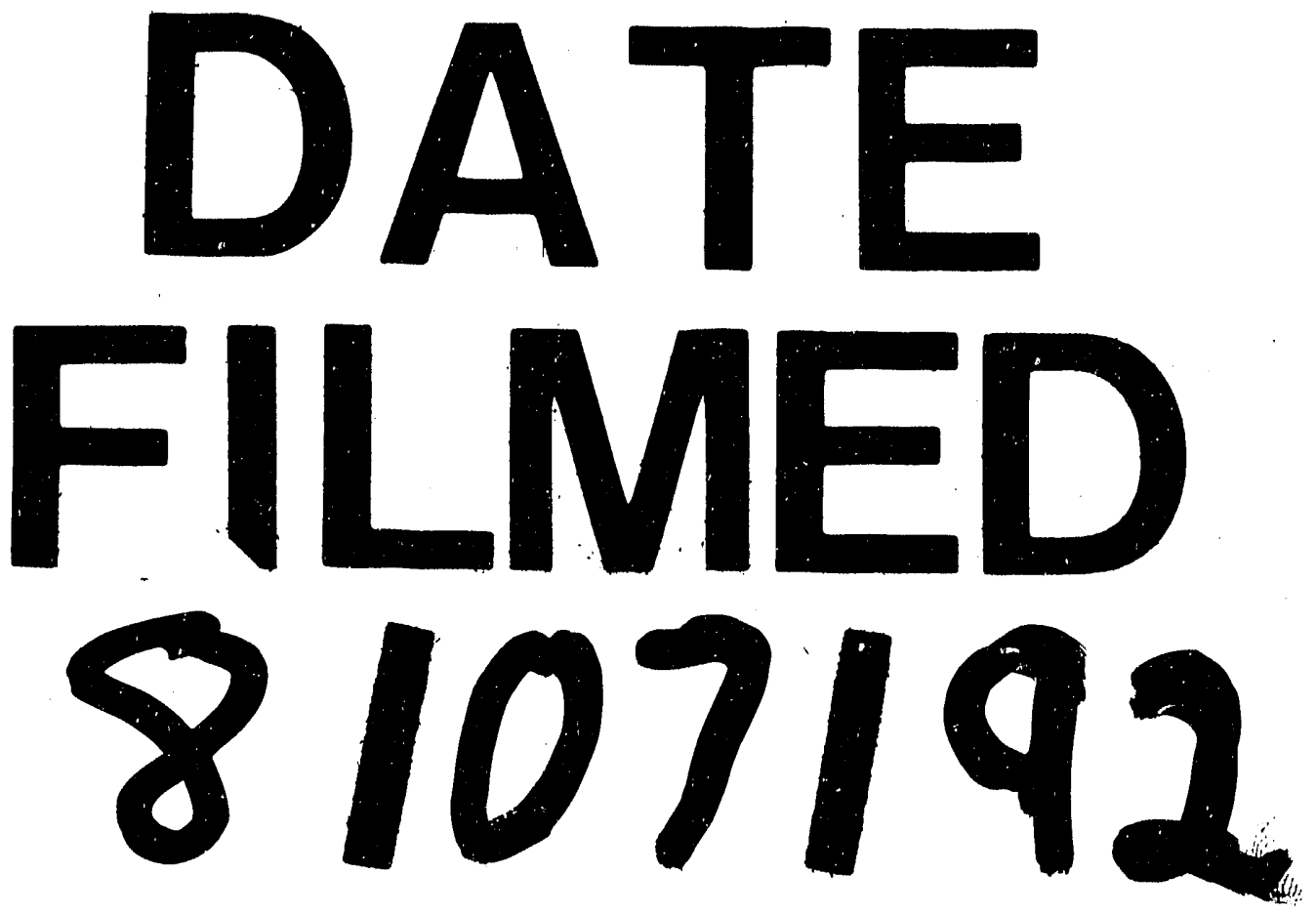
